\title{
The Creative Process and the Making of a Virtual Environment Work of Art
}

\section{Dena Elisabeth Eber}

\section{Introduction and Purpose}

Art is a human activity consisting in this, that one man [or woman] consciously by means of certain external signs, hands on to others feelings he has lived through, and that other are infected by these feelings and also experience them.

Tolstoy, from What is Art?, 1897

A work of art, according to Tolstoy (1898/1960), is sincere, and it transmits feelings through lines, colors, sound, or words. The feelings embedded in the imagery start with the creator and the creative process. The work may take any form, but to be art, the object, idea, or installation goes beyond the physical and contains some form of human experience. Art may be created with any tool, as long as the artist rises beyond that tool into an experiential realm. Many have debated the existence of the creative domain with the computer art medium, especially virtual environments (VE). With the tools to create a VE, the artist will learn a new technology that may influence the nature of and how she reaches the creative level. This is especially true when the technology, like VE, is an underdeveloped state, one which requires the artist to learn new techniques and pay close attention to the tool.

In addition to the acquisition of new information, the artist who chooses to work with VEs also has a new set of aesthetics to consider, as the final work of art is wholly different from that using any other medium. Contrary to the concepts expounded in the popular media, a VE art installation can be more that a display arena for the art of others (Picasso, for example) or a "shoot 'em up" computer game. It can be a work of art in and of itself, one that requires of the artist the same level of abstraction into the spirit of creativity as any traditional medium demands. How and at what point does the creative process happen for a VE artist in a world of computer peripherals and code?

This study will examine the creative process of an artist constructing a virtual environment work of art. By a VE, I mean computerized simulation of a scene that a viewer experiences using various computer peripherals. The experience is interactive, stereoscopic (true three dimensional display), and immersive. In the last few years, computers in general have made a mark in the world of art. Museums now show installations that include computers and work that was created using them. Art departments in public schools and universities are slowly adding corr puter classes, majors, and cor.centrations. Despite all the attention computers have gained in the art world, there is little or no research on the creative process of an artist using them. In fact, the computer is often thought of as an extension of traditional art rather than a stand alone medium. In the case of an artistic VE, the final product is the viewer's experience with the VE. This is 
a new medium with new aesthetics, creative thinking, and learning approaches for an artist making a VE installation. This specific study on the creative process for an artist making a fine art VE will reflect on perceptual and educational issues for students and artists making and leaning about computer art. The purpose of this study is to describe the nature of the creative process for a digital artist creating a VE work of art.

\section{Problem Statement}

A virtual environment (VE), also referred to as virtual reality (VR), is a synthesized world generated by a computer and its peripherals. This hardware may include a head mounted display (HMD) or an unencumbered cave environment, one that shows imagery and displays sound without peripherals (Kalawsky, 1993). Within this environment, the user interacts with and experiences three dimensional (3-D) spacialized sound and stereoscopic imagery which are responsive, in many cases, to his head and hand movements. Thus imagery and sound change as the user alters both head orientation and physical position in the world. The VE may instead, or in addition, track hand or other body movements, depending on peripherals. to be a true VE, the world is immersive, stereoscopic, interactive in real time, and provides a multimodal interface (National Research Council, Committee on Virtual Reality Research and Development, report, August, 1995).

In the last few years, virtual environments (VEs) have gained recognition as computer simulated worlds that can be used for diverse applications such as training pilots and soldiers for national defense and workers in hazardous operations, visualizing complex information and scientific data, manufacturing products, educating students, computer games, marketing products, and providing a work environment for its users. These VEs are designed by computer scientists, engineers, game designers, and specialists such as psychologists, aircraft designers, educators, and marketing professionals.

Most recently, a handful of artists have used the idea of VEs to create computer based virtual environment art installations. An art installation is a work of art that goes beyond an object that exists on a wall or behind glass, but encompasses an infinite number of artistic possibilities including alternative presentations, environmental constructions, multisensory stimulation, viewer interactivity, and theatrical performance. In short, an art installation is usually any art construction that goes beyond traditional presentation. Most of these so called VE works of art are either not true VEs, or they lack aesthetic consideration and content. This confusion is understandable as a result of overzealous media attention and the unrealistic expectations of VE.

Although there are many applications for VEs, researchers in the field are not considering their use as fine art installations (National Research Council.

Committee on Virtual Reality Research and Development, report, August, 1995) However, I believe such an environment will provide new aesthetics and experiences for both the artist creating the work and the user interacting with the work. Despite the opportunity to create art in a new medium with new aesthetics, 
there are relatively few artists who are producing VE works of art. As it is, artists must wade through misconceptions, hardware, and software in a world designed for computer scientists and engineers. These factors, along with the new characteristics of $V E$, pose a fresh set of aesthetic challenges.

Because the thinking and act of creating in this medium of art will extend ideas connected with the creative process, there is a need to explore the procedure that an artist goes through to produce a VE work of art. This process requires artists to explore and acquire the necessary hardware and software, learn to use the hardware and software, consider content and formal elements, think about the viewer's experience, define what a VE is for them, and ultimately go beyond the technology in order to express themselves through a work of art.

\section{Research Question}

This study will focus on the main research question:

What is the nature of the creative process for a digital artist making a VE work of art?

Because the nature of my research necessitates data collection and analysis simultaneously, new questions (or sub-questions) will emerge and also be addressed. Some of these questions related to the computer and VE art may include:

What is the relationship between the technology and the creative process?

Do gender issues in computer technology and environments affect the creative process?

Does the nature of the computer culture (both with the machinery and the other people involved) disrupt, change, discourage, or enhance the creative process?

What is the role of the aesthetic experience (if any) in the creative process?

How does the learning process influence the creative process?

How does the artist perceive the VE work of art (before and after creation)?

How do non-novice computer artists rise above the technology to make the VE?

Is the artist more concerned with the technology or the art?

How does the artist translate their artistic ideas into a VE? 
What aesthetic considerations - old and new - does the artist employ?

How does the artist consider the aesthetic experience of the viewer with their design?

\section{General Method}

My research question examines the ephemeral process of a person creating a VE work of art. This study will follow a phenomenological model in which the researcher attempts to understand the meaning of an event, person, or process to people in a given situation (Bogdan \& Biklen, 1992). The specific instance of the phenomenon is a case. A case study is the analysis of a single case as it is embedded in a system (Denzin, 1989), and the case is the bounded system. The bounded system is a case that "is an examınation of a specific phenomenon such as a ...process." (Merriam, 1988, p.9). For my study, the case will be the experience of creativity for an artist constructing an artistic VE. The experience is the bounded system, and it will include myself and one other participant. The participants are purposefully sampled for their experience and maturity as computer artists. I will act as a mentor and teacher for both and use a narrative method for collection, analysis, and presentation of the text. Specifically, I will use the personal experience narrative, which will necessitate myselt as the key data collection instrument. The many forms of narratives will include pre-histories, daily reflections and final reflections by the participants and researcher observation. This qualitative method will provide whole and vivid descriptions of the user's process of creation and will seek to inform VE designers, art educators, studio artists, and art critics about the nature of the creative process for VE works of art.

\section{Final Presentation and Analysis}

In the final layer of analysis, I will reread all the text with the aim of making sense of the creative experience for an artist construction a VE work of art. I will note emerging themes and differences and will create a final narrative that will embody the creation process for participants. My final summary will be a level of abstraction above the text, and will use the "progressive-regressive" (Denzin. 1989. p.67) method to reflect forward and backward from the entry into VE construction.

The final presentation will consist of the two personal history stories, the two final reflection stories, and the abstracted themes in the form of a final documentary narrative. The aim of the final narrative will be to explicate the emerging pattems that describe the nature of the creative process in artistic VE construction. Although this experience will be particular to artistically mature artists working with digital media, it has the potential to shed light on the experience of many artists learning about and creating art with the digital medium The results will ultimately inform educators about how to teach the digital art medium and artists about how to work with and think about it. 


\section{References}

Bogdan, R.C., Biklen, S.K. (1992). Qualitative research for education. Boston: Allyn and Bacon.

Denzin, Norman K. (1989). Interpretive biography. Newburry Park: Sage Publications).

Kalawsky, RoyS. (1993). The science of virtual reality and virtual environments. Wokingham, England: Addison-Wesley Publishing Company.

Merriam, Sharon B. (1988). Case study research in education, a qualitative approach. San Francisco: Jossey-Bass Inc.

National Research Council, Committee on Virtual Reality Research and Development (1995). Nathaniel I. Durlach, Anne s. Mavor (Eds.), Virtual reality: scientific and technological challenges. Washington, DC: National Academy Press.

National Research Council, Committee on Virtual Reality Research and Development (1995, August). National research agenda for virtual reality. Report presented at the meeting of the Special Interest Group, Graphics of the Association of Computing Machinery.

Tolstoy, Leo (1960). Extracts from What is art? In E. Simmons, Leo Tolstoy, VII (p. 239). New York: Vintage Books. (Reprinted from What is art?, [Aylmer Maude Trans.]. by L. Tolstoy, 1898, Oxtord: University Press) 